\title{
GIDA ENDÜSTRİSİNDE NANOSİSTEMLERİN KULLANIMI
}

\author{
Gülay Baysal* \\ Istanbul Aydın Üniversitesi, Mühendislik Fakültesi, Gıda Mühendisliği Bölümü, İstanbul, 34295, Türkiye \\ Geliş / Received: 07.01.2019; Kabul / Accepted: 28.04.2020; Online bask1 / Published online: 15.05.2020
}

Baysal, G. (2020). Gıda endüstrisinde nanosistemlerin kullanımı. GIDA (2020) 45(3) 517-529 doi: 10.15237 /gida.GD20012

Baysal, G. (2020). The use of nanosystems in the food industry. GIDA (2020) 45(3) 517-529 doi: $10.15237 /$ gida.GD20012

\section{ÖZ}

Nanosistemler, sağlık, gıda, enerii, tekstil, otomotiv, iletişim teknolojileri, tarım, silah ve uzay endüstrisi gibi birçok alanda kullanılmakta ve hayatımıza önemli gelişmeler kazandırmaktadır. Son yıllarda, nanosistemleri kullanarak, gıda ürünlerini atomik ve moleküler seviyelerde kontrol etmenin yollarını araştrrmak için birçok çalışma yapılmaktadır. Bu çalışmalar, yeşil paketleme sistemleri, oxo-biyobozunur paketleme sistemleri, gübre kullanımının sona ermesi, gıda takibi, izleme, marka koruması, biyosensörler, akıllı etiketler, lezzet hatalanı oluşturma, tat değişimi ve hızlı bakteri tespiti gibi başlıkları içermektedir. Bu çalışmalanın yanı sıra, sağlık alanında ilaç sektörü ve hastalıkların teşhis ve tedavisinde, hastanın konforunu önemli ölçüde arttırmakta ve ömrünü uzatmaktadır. Bu derleme çalışması, nanosistemlerin ve nanopartiküllerin kullanım alanlarını, gıda uygulamalarını, nanopartikül bileşenlerini (karbon nanotüpler, manyetik nanopartiküller, altın nanopartiküller, gümüş nanopartiküller ve kuantum noktalar), nanosensörleri, gida ambalaj sistemlerinde akıllı paketleme metotlarını ve biyosensörleri başlıklarını içermektedir.

Anahtar kelimeler: Nanosistemler, nanosensörler, biyosensörler, akı1lı etiketler

\section{THE USE OF NANOSYSTEMS IN THE FOOD INDUSTRY}

\begin{abstract}
The nanosystems are used in many fields such as health, food, energy, textile, automotive, communication technologies, agriculture, weapons and space industry and bring important improvements to our lives. In recent years, many studies have been carried out to investigate the ways to control the food products at atomic and molecular levels using nanosystems. These studies include topics such as green packaging systems, oxo-biodegradable packaging systems, end of fertilizer use, food tracking, tracking, brand protection, biosensors, smart labels, flavor defects, taste change and rapid bacterial detection. Besides, nanosystems significantly increase the patient's comfort and prolongs life in the diagnosis and treatment of the pharmaceutical industry and diseases in the field of health. This review study covers the usage areas of nanosystems and nanoparticles, food applications, nanoparticle components (carbon nanotubes, magnetic nanoparticles, gold nanoparticles, silver nanoparticles and quantum dots), nanosensors, smart packaging methods and biosensors in the food packaging systems.
\end{abstract}

Keywords: Nanosystems, nanosensors, biosensors, smart label

"Yazışmalardan sorumlu yazar/ Corresponding author

$\triangle$ gulaybaysal@aydin.edu.tr,

(f) (+90) $4441428-22409$

回 (+90) 2124255759

Gülay Baysal; ORCID no: 0000-0001-7081-1472 


\section{GİRİ̧̧}

Nanoteknolojide nanokompozitler önemli bir yere sahiptir. Gida endüstrisinde ambalajlama teknolojisinde yayginca gaz ve oksijen bariyeri, ince ambalaj filmleri, elektronik duyusal paketleme sistemlerinde ve renk taşıyıcı olarak kullanılmalarının yanı sıra damgalama, biyosensör, nanosensörler, akı1lı etiketler, hologramlar ve paketleme tasarımlarında da kullanılmaktadır. Nanokompozitlerin siklikla tercih edilmelerinin sebepleri ise termal kararlılıkları, mekanik dayanıklılıkları, boyutsal kararlılığ1 artırması, yüksek alev dirençleri, iyi bir yüzey görünümü, optik özellikleri ve güçlü gaz bariyer özellikleridir. Atom ve moleküllerin dizilimlerinin farklı tasarlanabilme kabiliyetleri beraberinde nanoçağ getirmektedir. 2020 yıllarında günlük yaşamımıza hızlı bir şekilde giriş yapan nanoteknoloji, beraberinde eşsiz ve büyüleyici yenilikleri getirmeye başlamıştır.

Nanoteknoloji, özellikle g1da endüstrisinde, gıdaların tekstür ve aroma gibi istenilen özellikte geliştirilebilmesine olanak sağlamıştır. Nanoparçacıklar kullanılarak, antimikrobiyal ambalajlar, biyobozunur materyaller, yenilebilir filmler üretilmekte ve raf ömrü güvence ve kontrol altına alınabilmektedir. Akıllı etiketler, biyosensörler ve nanosensörler kullanılarak gidaların bozulma belirtileri erken tespit edilebilmektedir (Joseph ve Morrison, 2006). Nanoteknolojinin gida endüstrisinde uygulama alanları olarak, gidalarda patojenlerin tespiti, gida güvenliğinin artırlması, antibakteriyel ambalaj sistemlerinin geliştirilmesi, biyoaktif maddelerin taşınması ile kontrollü salınım ve fonksiyonel gıda ürünlerinin geliştirilmesi başlıklarını sıralamak mümkündür (Robinson ve Morrison, 2009).

Gıdaların işlenmesi ve fonksiyonel ürünlerin geliştirilmesinde yaygınca nanoemülsiyonlar kullanılmaktadır. Nanoemülsiyonlar, nanodamlacıkları kullanarak, kremleşme ve sedimentasyonu önlemekte ve biyoaktif ürünlerin taşınmasını sağlamaktdır. Nanoemülsiyonlar hem gıdaların fiziksel görüntülerini iyileştirme, hem de nanokapsülleme yöntemiyle yağda çözünen besinlerin sindirimini kolaylaştırmaktadır (Mcclement, 2011). Buna ilaveten, biyoyararlıllı̆g1 da büyük ölçüde artırmaktadır (Zulli vd., 2006). Patojenlerin tespitinde ise, özellikle nanosensörler ve biyosensörler aktif olarak kullanılmaktadır (Cui vd., 2001). Patojenlerin gelişmesi ve çoğalmasında, zaman faktörü çok önemli bir parametre olduğu için saatler hatta dakikalar içinde patojenleri tespit edebilen nanosensörlerin geliştirilmesi büyük önem taşımaktadır (Bouwmeester vd., 2009; Garcia vd., 2006). Biyoaktif maddelerin taşınması ve kontrollü salınım sistemlerinin geliştirilmesinde ise kullanilan yayginca nanosistemler, nanokapsüllerdir. Nanokapsüller, mineral, protein, antioksidanlar ve vitaminler gibi gida bileşenlerinin biyoyararlılı̆̆ını artırmakta ve hedeflenen dokulara iletimini sağlayan sistemler olarak tanımlanmaktadır. Başlıca, gıdalarda uygulanan enkapsülasyon yöntemleri, hoş olmayan tat ve kokular1 maskelemek, biyoyararlılığ1 artırmak ve kontrollü salınımı gerçekleştirmek için uygulanmaktadır (Dion vd., 2008; Chaudhry vd., 2008; Serferty vd., 2010; Torres-Giner vd., 2007). Gida ambalajlarında ise, kullanılan ambalaj malzemelerinin gözenek sayısı, nem ve gaz geçirgenliği, gidaların korunması ve raf ömrünün uzaması üzerinde nanoteknolojinin etkileri büyük önem taşımaktadır. Özellikle, gıda ambalajlarında kullanımı, enerji sarfiyatlarını azaltmakta, gaz bariyer özelliklerini iyileştirmekte, $\mathrm{CO}_{2}$ emisyonunu düşürerek insan ve çevre sağlığını tehdit eden unsurları minimize etmektedir (Bente vd., 2000; Buzby 2010; Chau vd., 2007; Kirwan ve Strawbridge 2003). Yapilan araştırmalara göre, biyobozunur nanokompozit malzemelerin ambalaj tekniklerinde uygulanmas1, çevre dostu biyolojik ürünlerin geliştirilmesi anlamında büyük kazanım sağlamıştır (Cha ve Chinnan 2004; Dawson vd., 2002; Rhim vd., 2006).

\section{Nanopartiküller \\ Karbon Nanotüpler}

1991 yllında, karbon nanotüplerin sentezlenmesi, nanoteknoloji biliminin başlamasına ve bu alanda ki deneylerin hız kazanmasına neden olmuştur. Bilindiği gibi, karbon atomu 6 elektrona sahiptir, ancak ilk iki elektronun bağ oluşumuna katılmaması ve bağ yapımına katılan diğer 4 elektron ile aralarındaki enerji farkının oldukça 
büyük olması karbonun farklı yapilar oluşturabilmesine neden olmaktadır. Doğada bu özelliği taşıyan tek element karbon elementidir ve bu da onu eşsiz kılmaktadır. Karbon atomları kendi aralarında $\mathrm{sp}, \mathrm{sp}^{2}$ ve $\mathrm{sp}^{3}$ olmak üzere üç farklı bağlanma özelliği taşımaktadır. Karbon esaslı malzemeler, elmas, grafit, karbon şiberler, cams1 karbon, siyah karbon, amorf karbon, siv1 karbon, karbin ve karbolitlerden oluşmaktadır. Karbon nanoyapilar ise karbon nanotoplar, tek duvarlı karbon nanotüpler ve çok duvarlı (nanoçubuklar) karbon nanotüpler ve karbon nanohalkalardan meydana gelmektedir (Pandey vd., 2016). Karbon nanotüplerde katman sayısı ve katlanma şekline göre sınıflandırma yapılmaktadır. Elektriksel iletim özellikleri, en dış katmanın iletkenliğine bağlı olarak değişmektedir. $\mathrm{Bu}$ durum, yüzey fonksiyonlaştırma işleminin, elektronik özellikleri büyük ölçüde değiştirme nedenini, açıklayıcı niteliktedir.

Karbon nanoyapilar, metallerin espotansiyel yüzeyleri oluşturmasında etkili olduğu bilinmekle beraber optik sinirlayic1, fotoyansitici polimer, fotoiletken, fotodiyot, transistör, katalizör, süper iletken özellikleri ve güneş pillerinde yaygınca kullanılan materyallerdir (Küçükyıldırım vd., 2012; Cumbul vd., 2014; Flahaut vd., 2012). Karbon nanotüplerin üretimi için ark deşarj, lazer kazıma ve kimyasal buhar biriktirme yöntemleri kullanılmaktadır.

\section{Manyetik Nanopartiküller}

$\begin{aligned} & \text { Nanopartiküller, bloklama } \\ & \text { üzerindeki }\end{aligned}$ (Tc) $\begin{array}{r}\text { sicaklığının } \\ \text { değerlerinde }\end{array}$ süperparamagnetik özellik gösterirler. Demir $(\mathrm{Fe})$, kobalt (Co), magnetit ve maghemit gibi demir oksitler, ferrimagnetler, $\mathrm{CoPt}_{3}$ ve FePt gibi bazı alaşımlar manyetik nanopartiküllerin bileşenlerini oluşturmaktadır (Erdoğan, 2018; Gubin vd., 2005). Manyetik nanopartiküller, termal parçalanma, hidrotermal sentez, ortak çöktürme ve mikroemülsiyon gibi metotlar ile sentezlenebilmektedir. Parçacık boyutu azaldıkça, spinler termal dalgalanmalardan etkilenir ve parçacıklar süperparamanyetik hale gelir (Vatta vd., 2006). Yaygın olarak, ilaç sektöründe ilaç taşıyıcı olarak, manyetik cihaz tasarımlarında ve biyoteknolojide hücre, protein, nükleik asitler, enzim, bakteriler, virüsler gibi biyomolekülleri ayırmak ve klinik tanı ve tedaviler için kullanılmaktadırlar. Bunun yanı sıra, özellikle kemoterapi ve radyoterapi gibi tedavi yöntemlerinde hyperthermia adlı destek tedavi yöntemi olarak kullanılabilmektedirler (Erdoğan, 2018; Abu-Dief vd., 2018). Manyetik nanoparçacıklar, değişen manyetik alana maruz bırakıldıklarında manyetik histerisis kayıplariyla 1sınır. Tümör hücreleri 1sıya karşı oldukça duyarlıdır ve $41{ }^{\circ}$ C'de bozulmaya uğrarlar. Şekil 1 'de manyetik nanopartiküllerin çalışma mekanizmaları şematize edilmiştir.

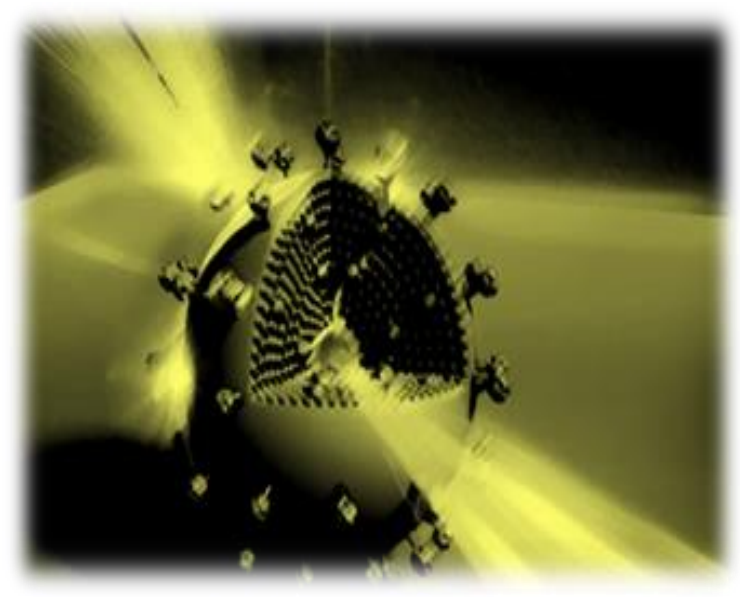

Şekil 1. Manyetik nanopartiküllerin çalışma mekanizmalar1

Figure 1. The working principles of magnetic nanoparticles

\section{Altın Nanopartiküller}

Altın, makroskobik olarak kararli, yüksek redoks potansiyeline sahip, korozyona karşı dirençli, yüksek yoğunluklu bir elementtir. Altın nanopartiküller, optik dalgalar ile etkileşerek spesifik renklerini ve yarı iletkenlik özelliklerini oluştururlar. Altın nanopartiküllerin boyut, şekil, erime hızı, yükü ve büyük yüzey alanı gibi özellikleri biyolojik etkileşimlerde ki aktivitelerini önemli ölçüde geliştirmektedir. Altın nanopartiküller, elektromanyetik spektrumunda geniş bir emilim bandına sahiptir. Işık adsorplama kapasiteleri, organik boyalardan bir milyon kat daha fazladır. Radyoaktif özellik göstermedikleri için 1s1 açı̆̆a çıkarabilmektedirler, bu nedenle kanser tedavilerinde sıkça tercih edilmektedirler. 
Bununla birlikte biyouyumlu olma özellikleri kullanım yelpazelerinin genişlemesine neden olmuştur (Shah vd., 2014; Slepicke vd., 2020).

Altın nanopartiküllerin (AuNP) kendilerine özgü fiziksel, kimyasal, elektronik ve optik özellikleri, nanoteknolojide aranan nanopartiküller olmalarını sağlamıştır. Bir soy metal olan altın toksik özelliğe sahip olmadı̆̆ için kanser tedavilerinde yayginca tercih edilmektedir. Pankreas ve akciğer kanserinde, ilaç salınım sistemlerinde, sitotoksikolojik çalışmalarda altın nanopartiküllerin aktif rol oynadıkları bilinmektedir (Das vd., 2011; Yadav, 2018). Son zamanlarda, tümör antimikrobiyal, antimalaryal ve anti-HIV aktivitelerine sahip çeşitli "organoaltın" kompleksleri ortaya çıkmışır.

\section{Gümüş Nanopartiküller}

Gümüş, bakteri direncini neredeyse yok eden, geniş spektrumlu, antimikrobiyal, antifungal ve antiviral bir elementtir. Bakır, titanyum ve altn gibi elementler ile kıyaslandığında, en çok antimikrobiyal etkiyi gümüş elementi göstermektedir. Bakterinin hücre duvarına bağlanarak, proteinlerle etkileşmesi sonucu bakterinin hücre zar geçirgenliğini azaltır. Bakteri hücresinin yapisinda ki tiol, karboksil, amin, fosfat, indol, imidazol ve hidroksil grupları ile etkileşime girerek hidrojen katyonuyla yer değiştirir ve DNA molekülün zarar görmesini sağlar. Mikroorganizmada solunum zincirlerindeki enzimleri etkisiz hale getirerek oksidadif fosforilasyonundaki elektron taşıma sistemini çökertir. Bu etki, özellikle serbest radikallerde meydana gelir. Yapılan araştırmalara göre gümüş iyonları, gümüş nanopartiküllere göre daha toksiktir. Gümüss nanopartiküller, biyosensör uygulamalarında yayginca kullanılmaktadır. Bunun nedeni ise, yüksek iletkenlikleri sayesinde biyosensörlerin içinde ki elektron iletimini kolaylaştırması ve ölçümlerin hassasiyetini arttırmasıdır (El-Nour vd., 2010; Rauwel vd., 2015; Jafari vd., 2015). Şekil 2'de gümüş nanopartiküllerin virüslerin DNA dizilimlerinde oluşturduğu bozulma etkisi gösterilmektedir.

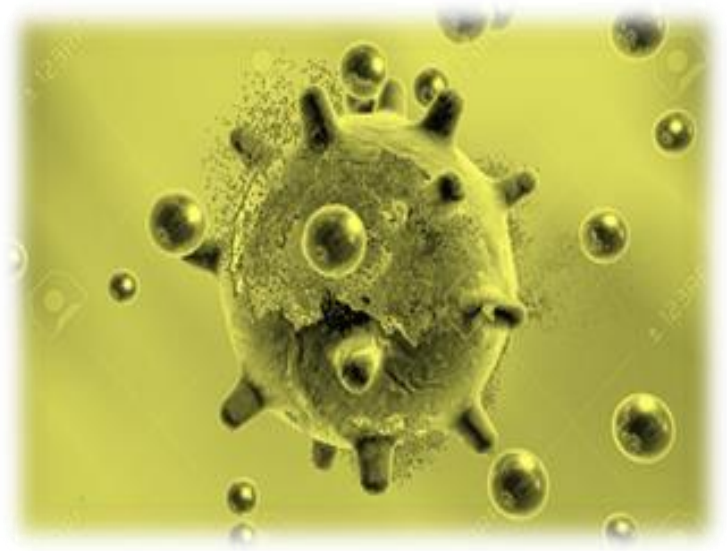

Şekil 2. Gümüş nanopartiküllerin, virüslerin DNA dizilimlerinde oluşturduğu bozulma etkisi Figure 2. The destruction effect of silver nanoparticles on $D N A$ sequences of viruses

\section{Kuantum Noktalar}

Kuantum noktaları yarı iletken ve atomik düzeyde (2-10 nm) tanecik boyutuna sahip nanokristallerden oluşmaktadır. Tanecik boyutlarının kontrol edilebilir olması, kuantum noktalarına çok geniş kullanım alanları sağlamaktadır. Bu yarı iletken nanotanecikler farklı enerji seviyeleri ve optik özelliklerinden dolayı lazer sistemleri, biyoteknoloji, elektronik sistemler, 1şık yayan diyotlar ve güneş pili çalışmaları gibi birçok alanda kullanılmaktadır. Özellikle tup ve biyoteknolojide hastalıklann görüntüleme yöntemleriyle hızlı ve doğru teşhis edilmesinde ve gen tedavilerinde aktif olarak rol almaktadırlar. Şekil 3'de örnek kuantum noktalarının yapısı gösterilmektedir.

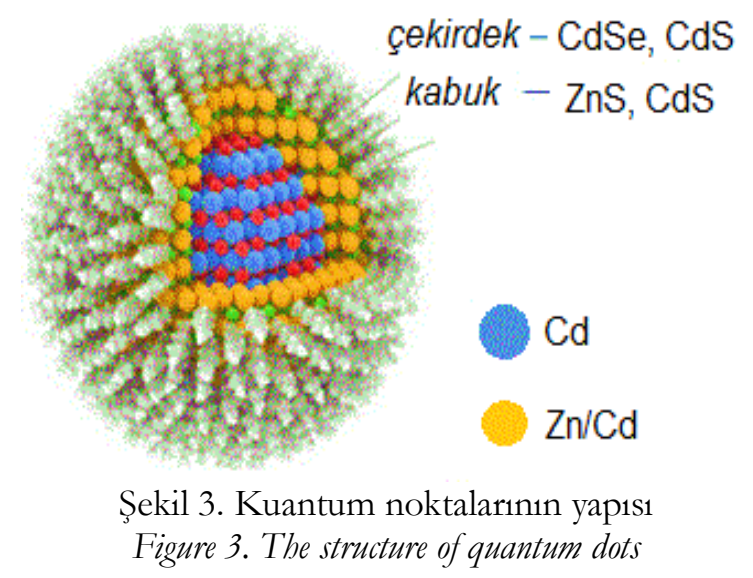


Kuantum noktaları peryodik tabloda II-VI ve III$\mathrm{V}$ grubu elementlerinden elde edilmektedir. $\mathrm{Bu}$ nanotaneciklere başlica CdSe ve CdTe ya da InP ve InAs gibi bileşikler örnek verilebilir. Kuantum noktalarının yüzey kimyaları amin, karboksil ya da merkapto gibi reaktif grupların biyomoleküllere bağlanması sonucu meydana gelmektedir. Ancak, bu nanokristal bileşiklerinde mevcut olan kadmiyum gibi ağır elementler hücrelerde toksisiteye neden olmaktadır. $\mathrm{Bu}$ nedenle kuantum noktalarınin sentezlenmesinde $\mathrm{CuInS}_{2} / \mathrm{ZnS}, \mathrm{PbS}$, InP, InAs/InP/ZnSe gibi bileşenler tercih edilse bile, bu bileşiklerin absorbanları düşük olduğu için özellikle görüntüleme sistemlerinde kadmiyum bileşikleri ile aynı performansı gösterememektedir. $\mathrm{Bu}$ sorunu önlemek için, kuantum noktalarının dış yüzeyleri biyouyumlu malzemelerle kaplanarak veya ligand grupları bağlanarak toksisite önemli ölçüde azaltılmaktadır (Özkan Vardar vd., 2018).

Kuantum noktalarınin uygulama alanları, biyomoleküllerin ve hücrelerin etiketlenmesi, hücre içi / hücre dışı takip edilmesi, tek bir biyomolekül / hücrenin dinamiği, biyomoleküllerin in vitro / in vivo lokalizasyonu, biyomoleküllerin veya hücrelerin in vitro / in vivo görüntülenmesi, hasarlı dokuda hücre büyümesinin değerlendirilmesi, $\mathrm{pH}$ probları enzim reaksiyon kinetiği, çeşitli kanserlerde biyomarker tespiti, bulaşıcı hastalıkların görüntülenmesi ve algilanması veprotein mikrove nano-dizileri olarak kanser biyobelirteçlerinin saptanması başlıklanı altında verilebilir (Valideh vd., 2012).

\section{Nanosensörler}

Tip alanında genetik taramalarda, klinik tanımlamalarında, ilaç keşiflerinde, kinetik ölçümlerde, ilaç bağlama mekanizmalarında olmak üzere daha birçok alanda kullanilan nanosensörler, biyomoleküler etkileşimleri doğru zamanlı ve hassas olarak ölçme kabiliyetine sahiptirler (Wang vd., 2019). Yapilan araştırmalar, lazer girişimi litografisi ve iyon aşındırma işlemleriyle silikon oksit kullanılan zeminler ve polietilen teraftalat (PET) gibi polimer kaplama levhalarının kullanıldığı teknolojiler uygulandığını göstermektedir. UV 1şınlama sonrası soyulan polimer kaplamalar ile metal ve oksitleri üzerinde biriktirmiş nanokaplar elde edilmektedir. Yine benzer çalışmalarda özellikle altın (Au) JimenazLopez vd., 2019) ve titanyum dioksitin $\left(\mathrm{TiO}_{2}\right)$ kullanıldığ1 nanosensörlere oldukça fazla rastlanilmaktadir (Dang vd., 2019). Titanyum bilindiği gibi biyouyumlu, kararlı, korozyona dayanıkl, manyetik olmayan ve düşük yoğunluklu bir metal olduğu için sıklıkla kullanımı tercih edilmektedir. Çizelge 1'de yapılan literatür araştırmalarına göre bazı nanosensörler ve kullanım alanlanı örneklendirilmiştir.

Çizelge 1. Literatüre göre bazı nanosensörlerin kullanımı

Table 1. Use of some nanosensors according to the literatüres

\begin{tabular}{|c|c|c|}
\hline Kullanm amacr & Nanosensörler & Kaynaklar \\
\hline Okratoksin tespiti & Siyah fosfor nanosensörleri & (Xiang vd., 2018) \\
\hline Antikanser ilaçlar & SPR nanosensörleri & (Özkan vd., 2019) \\
\hline Civa iyonlarınin tespiti & Multi model nanosensörler & (Satapathi vd., 2018) \\
\hline Serum albümin tespiti & Kopolimer nanosensörler & (Rezende vd., 2017) \\
\hline Sistin tespiti & Kolorimetrik nanosensörler & (Li vd., 2019) \\
\hline Uçucu organik bileşiklerin tespiti & Kolorimetrik nanosensörler & (Ziyaina vd., 2019) \\
\hline Hekzasiyanoferratın antioksidant tespiti & Elektrokimyasal nanoelektrotlar & (Arman vd., 2019) \\
\hline Kadmiyum iyonlarının tespiti & $\begin{array}{l}\text { Kuantum nokta bazlı floserans } \\
\text { nanosensörler }\end{array}$ & (Qian vd., 2017) \\
\hline Acil durum stratejileri & $\begin{array}{l}\text { AuNP-bazlı ICTS } \\
\text { nanosensörleri }\end{array}$ & (Zhou vd., 2019) \\
\hline Organik moleküllerin tespiti & $\begin{array}{l}\text { AuNP-bazlı plazma } \\
\text { nanosensörleri }\end{array}$ & (Veglia vd., 2019) \\
\hline Kurkumin tespiti & Karbon-bazlı nanosensörler & (Gong vd., 2019) \\
\hline
\end{tabular}


Doğal gaz kullanımının dünyada yaygınlaşmasıyla beraber risk faktörleri de ortaya çıkmaktadır. Bu amaçla, patlayıcı ve tehlikeli gazların hızlı bir şekilde tespit edilmesinde nanokompozitler ve nanosensörler kullanılmaktadır.

Gıda endüstrisinde kullanılan nanosensörler, g1da proses, g1da kalite kontrol, g1da güvenliği, g1da ambalaj ve etiketlerinde, g1da depolama, raf ömrü, mikrobiyal kontaminasyon (Kumar vd., 2019), toksinlerin ve kontaminasyonların tespiti gibi alanlarda yayginca kullanılmaktadır. Kullanılan nanosensörlere manyetik nanopartiküller (MNPs), gümüş nanopartiküller ( $A g N P S)$, altın nanopartiküller $(A u N P s)$, dönüştürücü nanopartiküller, kuantum noktalar (QDs), tek duvarlı karbonnanotüpler (SWNTs), çok duvarlı karbon nanotüpler (MWNTs), nanobarkod teknolojisi ve elektronik burun teknolojileri örnek verilebilir (Srivastava vd., 2018).

$\mathrm{Au}$ elementi ve $\mathrm{ZnO}$ bileşikleri sıklıkla nanotellerin tasarımında kullanılmaktadır (Lupan vd., 2019; Lupan vd., 2019). Membran hedefli yar1 iletken gerilim nanoşeritler tıp alanında oldukça fazla kullanılmaktadır. Benzer çalışmalarda $\mathrm{ZnSe} / \mathrm{CdS}$ nanoşeritlere, altın (Au), dekstrin gibi polisakkarit kaplamalarına rastlamak mümkündür (Park vd., 2019). Gıda üretim ve dağıttm sistemlerinde nanosensörlere ihtiyaç oldukça fazladır. Farklı metotlarla floresans renkler yayan nanopartiküller kullanılarak zararlı patojenler hızlı bir şekilde sayı ve tür olarak tespit edilmektedir. Nanosensörlerin tasarımında dikkat edilmesi gereken özellikler ise seçicilik, kalibrasyon gereksinimi, tekrarlanabilirlik, stabilite, yüksek duyarlılık ve geniş ölçüm aralığıdır. Yapılan literatür çalışmalarında farklı amaçlarla birçok nanosensör sentezlenmiştir. $\mathrm{Bu}$ çalış̧malara, ochratoxinin elektrokimyasal tespitinde siyah fosforen katmanll, iki boyutlu nanosensörler tasarlamıslar ve cam karbon elektrotlan, karbon nanotüpler ile modifye edilmesi örnek olarak verilebilir (Xiang vd., 2018). Özkan vd., 2019, etoposide kemoterapi ilaçlanında kullanılmak üzere boron nitrit nanotabakalar ile yüzey plazmon rezonans (SPR) nanosensörler geliştirmişlerdir. Satapathi vd., 2018, civa iyonlanını hassas olarak algılayabilen multimodal nanosensörlerin

sentezlenmesinde süperparamanyetik $\mathrm{Fe}_{2} \mathrm{O}_{3}$ nanopartiküllerini kullanmışlardır. Bilindiği üzere sığır albüminleri hayvan sağlığı ve süt kalitesi için belirleyici bir role sahiptir.

Rezende vd., 2017, doğal sığır serum albüminlerini tespit etmek için polidiasetilen/triblok kopolimer nanosensörlerini tasarlamışlardır. Li vd., 2019, sistin belirlenmesinde aspartik asit ve seryum nitrat $\mathrm{Ce}$ $\left(\mathrm{NO}_{3}\right)_{3}$ kullanarak kolorimetrik nanosensörler tasarlamıştır. Qian vd., 2017, kadmiyum iyonlarının belirlenmesinde silika tabakalarını kullanarak ratiometrik floresans nanosensörler sentezlerken CdTe kuantum noktalar kullanmışlardır. Zhou vd., 2019, altın nanopartikül esaslı şerit nanosensörler sentezlemiş, Gong vd., 2019, kurkuminin kantitatif olarak tespit edilmesi için karbon esaslı kimyasal nanosensörler sentezlemişlerdir. $\mathrm{Bu}$ çalışmalar önderliğinde nanosensörlerin yapılmasında kullanılan nanopartikülleri metalik nanopartiküller, manyetik nanopartiküller, dönüştürücü nanopartiküller, kuantum noktalar, grafenoksit ve karbon nanotüpler olarak sinıflandırabiliriz (Srivastava vd., 2018).

Gıda ambalajlannda ve kalite kontrol aşamalarında özellikle gaz sensörleri ve biosensörler kullanılmaktadır. Gaz sensörleri potensiyometrik karbondioksit sensorleri, polimer esasl1 sensorler, piezoelektrik kristal sensorleri ve amperometrik oksijen sensorlerinden oluşmaktadır. Optokimyasal sensörler ise daha çok mikrobiyal bozunmaları ve kontaminasyondan dolayı gida bozunmalarını belirlemek amacıyla kullanılmaktadırlar. Gıdaların tazeliğini kontrol edebilmek için ise biosensörlerin kullanımına başvurulmaktadır (Gök vd., 2007).

\section{Gıdalarda akıllı paketleme sistemleri}

Akıllı paketleme sistemleri, gıda ürünlerinin uygun çevre koşullarında ve kalite standartlarında muhafaza edilerek tüketicinin sofrasina taşınmasını sağlayan takip, izleme ve kontrol etme mekanizmalarıdır. Gıdanın üretimi ve tüketimi arasında uzun bir zincir vardır. Bu zincirin her bir halkasında gidaları takip eden sistemlerin 
oluşturulması taze ve sağlıklı gıda tüketimi için zorunlu hale gelmektedir. Veri iletme ve veri depolamada taşıyıcı olarak barkodların kullanılması en popüler ve ucuz olan yöntemlerden biridir. Ancak "evrensel ürün kodu (UPC)" barkodlarına yeterli veri girişi sağlanamadığ için gida güvenliğini sağlamada yetersiz bir metottur. Radyo frekanslı tanımlama (RFID) ise ürün tanıma ve izlemede yardımcı olan bir sistemdir. Etiket, anten, okuyucu, sorgulayıc1 ve denetleyici olmak üzere beş temel bileşenden oluşan bir sistemdir. Gida ürünlerinin depolanmas1 ve yerleştirilmesinin kontrollü yapılması, ürünlerin çıkış/giriş kontrol sürelerinin azalması, ürün satışlarının anında belirlenmesi, son kullanım tarihlerinin izlenebilmesi, firelerin ve maliyetlerin azalması RFID sistemlerin avantajları olarak belirtilmektedir (Kocaman vd., 2010; Fuertes vd., 2016).

Ak1ll paketlemede sistemlerinde depolama ve bekleme aşamasında ürün ambalajını, çevreyi kontrol eden ve veri desteği sağlayan indikatörler ve biosensörler olmak üzere iki farklı metot bulunmaktadir.

\section{Biyosensörler}

Biyosensörler, reseptör ve dönüştürücü bileşenlerinin bir araya getirilmesi sonucu ortaya çıkarlar. Reseptörler, biyomoleküler bir yapıya sahiptir. Analitlerin, biyolojik algilayıcılann (Enzimler, antikorlar, immuno ajanlar, nükleik asitler, mikroorganizmalar, hücreler, dokular ve seçici olarak etkileşimde bulunan fizikokimyasal dönüştürücülerin (elektrotlar, transistörler, termistörler, optik fiberler, piezoelektrik kristaller) bir araya getirilmesi sonucu fiziksel sinyaller ölçülür. Özellikle gidalarda antioksidan analizleri için en sıcça kullanılan yöntemlerden biri kolorimetrik biyosensörlerdir (Mukdasai vd., 2019). Ölçülen bu fiziksel sinyallerden elektriksel sinyalleri elde edilir (Tüylek vd., 2017). Biyosensörlerin çalışma prensipleri bu temele dayanmaktadır. Çizelge 2'de bu konuda yapilan literatür araștırmalarının özetleri yer almaktadır.

Çizelge 2. Literatürlere göre bazı biyosensörlerin kullanım alanlan

Table 2. Usage areas of some bioosensors according to the literatïres

\begin{tabular}{|c|c|c|}
\hline Kullamm amact & Biyosensörler & Kaynaklar \\
\hline Lizozimin tespiti & Aptamer-bazlı elektrokimyasal biyosensör & (Khan vd., 2018) \\
\hline Arsenik ve civa tespiti & Metalotiyonin bazlı biyosensör & (Irvine vd., 2017) \\
\hline Malehit yeşili tespiti & Mikro kantilever bazlı optik biyosensör & (Zhao vd., 2019) \\
\hline $\begin{array}{l}\text { 3-metilkinoksalin-2-karboksilik asit } \\
\text { tespiti }\end{array}$ & SPR biyosensör & (Qian vd., 2019) \\
\hline Escherichia coli tespiti & Amperometrik biyosensör & (Dhull vd., 2019) \\
\hline Kanser tespiti & İzomeraz bazlı biyosensör & (Ahmad vd., 2019) \\
\hline Mikroakışkan teknolojisi & SERS bazlı nanosensör & (Teixeira vd.,2019) \\
\hline Shigella spp tespiti & Floresans nano biosensörler & (Elahi vd., 2019) \\
\hline Rodamin B nin tespiti & Ratiometrik biosensörler & (Li vd., 2019) \\
\hline Mikotoksinlerin tespiti & SPR biosensör & $\begin{array}{l}\text { ( Mahmoudpour vd., } \\
\text { 2019) }\end{array}$ \\
\hline Aflatoksin B1 tespiti & Elektrokimyasal biosensörler & (Selvolini vd., 2019) \\
\hline Aflatoksinin çıplak gözle tespiti & Kolorimetrik biyosensör & (Wu vd., 2019) \\
\hline
\end{tabular}

Nanoteknolojinin, biyosensörlerin yapımında kullanılmasının bazı önemli avantajları bulunmaktadır. Nano elektronik parçacıklar biyosensörlerin bellek ve işlem yeteneklerini artırdığı gibi, analizlerin kolaylaşmasını da sağlamaktadır. Buna ilaveten mikroorganizmaların teşhisini kolaylaştırma, yüksek seçicilik ve uzun ömürlü olmalarını da sağlamaktadır (Aydın vd., 2019). Aynı zamanda canlı hücrelere zarar vermeden çalışma imkânı sunmaktadır (Tüylek vd., 2017).

\section{İndikatörler}

Gıdaların biyolojik bozulması, karbon içeren kimyasal bileşiklerin ayrılma süreçleri olarak tanımlanabilir. Canlı organizmaların salgıladığı 
enzimler ise bozulma için uygun koşulların oluşmasını sağlar. Bozulma süreçleri sıcaklık, nem ve mikroorganizma türemesi ile gerçekleşmektedir. Gida ürünlerinin sıcaklık geçmişi, tazeliği ve mikrobiyotası hakkında takip sisteminin en başında zaman-sıcaklık indikatörleri ve tazelik indikatörleri gelmektedir.

\section{Zaman-S1caklık indikatörleri (TTI)}

Zaman-sıcaklık indikatörleri, taşıma, dağıtım ve depolama süreçlerinde gida ürünlerinin değişen ortam sıcaklıklarının ölçümüne dayanır. Kritik sıcaklıklardan sapmaları göstererek ürünün güvenliğini kontrol altında tutmaya çalışan sistemlerdir. Zaman-sıcaklik indikatörleri difüzyon bazlı, enzim bazlı ve polimer bazlı olmak üzere üç çeşit olarak incelenirler. Zaman-sıcaklık indikatörleri, indikatördeki renk değişimleri ile birlikte genellikle mekanik, kimyasal, elektrokimyasal, enzim ve mikrobiyal değişiklikleri ölçer. Bu akıllı etiketler işlem boyunca referans sıcaklık sapmalarını ve sıcaklık değişikliklerini gösterir (Gök vd., 2006).

\section{Difüzyon-bazlı indikatörler}

$\mathrm{Bu}$ etiketlerde indikatör olarak genellikle ester boyaları kullanılır. Farklı erime sıcaklığına sahip kimyasalların kurutma kağıdından yapılmış bir fitile difüzyonu ilkesine dayanır. Sicaklık değiştikçe indikatör renk değiştirir.

\section{Enzim-bazlı indikatörler}

Lipitler, sıcaklık artışıyla içsel basınç oluştuğunda enzimatik hidrolize uğrar ve ortamda kaproik asit benzeri asit bileşenleri oluşarak ortam $\mathrm{pH}$ değerini düşürür ve asitliği artırrr. Böylece $\mathrm{pH}$ indikatörünün rengi değişir. Ürüne özgü sıcaklık değerlerine uygun olarak enzim-lipit bileşenlerinin konsantrasyonları ayarlanabilmektedir (Gök vd., 2006).

\section{Polimer-bazlı indikatörler}

Diasitilen kristallerinin polimerizasyon sırasındaki renk değişikliğine bağlı olarak sıcaklık değişiklerini göstermektedir.

\section{Tazelik İndikatörleri}

Tazelik indikatörleri, mikrobiyal bozunma esnasinda meydana gelen metabolitleri ve gaz konsantrasyonlarını tespit etmeye yönelik bir sisteme dayanır. Bu etiketler genellikle modifiye atmosfer paketleme (MAP) sistemlerinde kullanılmaktadırlar. Mikrobiyal metobolitlere, $\mathrm{pH}$ değişimlerine, hidrojen sülfür ve uçucu nitrojen bileşiklerine duyarlı indikatörler olmak üzere 4 başlıktan oluşmaktadır (Gök vd., 2007). Genel olarak gida endüstrisinde kullanilan bazı indikatörler ve kimyasal içerikleri Çizelge 3'de gösterilmektedir.

Çizelge 3. Gida uygulamalarında indikatör türleri ve kimyasal yapıları

Table 3. The chemical structure and indicators type in food applications

\begin{tabular}{|c|c|c|c|}
\hline \multicolumn{2}{|l|}{ Indikatör tipi } & Kimyasal ayıraç & Gida uygulamalar \\
\hline \multirow{3}{*}{$\begin{array}{l}\text { Zaman-sicaklik } \\
\text { indikatörleri } \\
\text { (TTI) }\end{array}$} & Difüzyon bazlı & ester boyaları & Soğuk zincir ve \\
\hline & Enzim bazlı & $\begin{array}{l}\text { Lipaz substratı ve enzimler, } \mathrm{pH} \\
\text { indikatör boyaları }\end{array}$ & gidalarda. \\
\hline & Polimer bazlı & diasetilenik monomerler & \\
\hline \multicolumn{2}{|l|}{$\mathrm{O}_{2}$ indikatörü } & $\begin{array}{l}\text { Redoks ve } \mathrm{pH} \text { boyaları (Fe/asit, } \\
\text { enzimler) }\end{array}$ & $\begin{array}{l}\text { Vakumlanmıs ambalajlar (ekmek, } \\
\text { kek, pizza, peynir, et ve balık, kahve, } \\
\text { kuru gıdalar vs.). }\end{array}$ \\
\hline \multicolumn{2}{|l|}{$\mathrm{CO}_{2}$ indikatörü } & $\begin{array}{l}\mathrm{CaO} / \text { aktif karbon, } \\
\text { askorbat/ } \mathrm{NaHCO}_{3}\end{array}$ & $\begin{array}{l}\text { Modifiye atmosfer paketleme (et, } \\
\text { balık, yağlı tohumlar, kahve vb.). }\end{array}$ \\
\hline \multicolumn{2}{|l|}{ Etilen tutucular } & Aktif karbon, $\mathrm{KMnO}_{4}$ & Tahil ürünleri, meyve ve sebze. \\
\hline \multicolumn{2}{|l|}{ Etanol salicilar } & Kapsüllenmiş etanol & Pizza, ekmek ve balık. \\
\hline \multicolumn{2}{|l|}{ Renk indikatörleri } & redoks ve $\mathrm{pH}$ boyalar1 & Mikrodalgada hazırlanan gidalar \\
\hline \multicolumn{2}{|l|}{ Nem tutucular } & silika jel & Sebze, meyve, balık ve kuru gidalar. \\
\hline \multicolumn{2}{|c|}{ Koku tutucular } & Sitrik asit, aktif karbon & Günlük gidalar, et ve balık. \\
\hline \multicolumn{2}{|c|}{$\begin{array}{l}\text { Mikrobiyal metabolitlere duyarlı } \\
\text { indikatörler }\end{array}$} & $\begin{array}{l}\text { Alkol oksidaz, peroksidaz ve } \\
\text { kromojenik bir substrat }\end{array}$ & Sebze ve meyveler. \\
\hline \multicolumn{2}{|c|}{ pH değişimine duyarlı indikatörler } & $\mathrm{pH}$ boyaları & Et ve balık. \\
\hline
\end{tabular}




\section{SONUÇ}

Son yıllarda, sağlıklı gıda üretim ve tüketim proseslerinde, gelişen teknolojiler sayesinde oldukça önemli gelişmeler yaşandığ 1 görülmektedir. Bilinçli tüketici olgusunun dünyada yaygınlaşması, beraberinde mevcut sorunlara hızlı, ucuz, doğru ve kalıcı çözümler üretme anlamında nanopartiküller, nanosensörler, biyosensörler ve akılll paketleme sistemleri gibi bilimsel araştırmalara yoğun ilgi kazandırmaktadır. Gıdalar üzerinde moleküler boyutta gerçekleştirilen değişimler, istenilen formlarda ve fiziksel özelliklerde gidaların üretilmesine olanak sağlamaktadır. İstenilen sicaklı̆ga dayanıklı çikolatalar, çok az miktarda yağ ile kızarabilen patatesler, kalorisi düşük mayonez ve hamburgerler, kilo yapmayan dondurmalar, kolesterolü yükseltmeyen kuruyemiş ürünleri, tansiyon ve şeker hastalıklarını tetiklemeyen tuzlu ve tatlı gidalar, kalorisi düşük unlu mamuller nanoteknoloji ve nanosistemler ile artık hayal ürünü olmaktan çıkmaktadır. Gıda endüstrisinde, bu yeni ve heyecan verici uygulamaları, taşıma sistemleri (miseller, nanoemülsiyonlar, liposomlar ve biyopolimerik nanoparçacıklar), gıda güvenliği, biyogüvenlik (nanosensörler, biyosensörler, akıllı ambalaj sistemleri) ve nanotoksisite gibi gida uygulamalar1 takip etmektedir. Gelişen teknolojilerin hızlı bir şekilde endüstrileştirilmesi hayatı her alanda kolaylaştırmakta, konfor seviyesini artırmakta ve yeni geliştirilecek teknolojilere ilham kaynağı olmaktadır.

\section{KAYNAKLAR}

Abu-Dief, A.M., Abdel-Mawgoud, A.A.H. (2018). Functionalization of magnetic nanoparticles for Drug Delivery. SF J Nanochem Nanotechnol, 1(1):1005.

Ahmad, L., Salmon, L., Korri-Youssoufi, H. (2019) Electrochemical detection of the human cancer biomarker 'autocrine motility factorphosphoglucose isomerase' based on a biosensor formed with a monosaccharidic inhibitör. Sens Actuators B Chem, 299:126933.

Arman, A., Üzer, A., Sağlam, Ş., Erçağ, E., Apak, R. (2019). Indirect electrochemical determination of antioxidant capacity with hexacyanoferrate (III) reduction using a gold nanoparticle-coated ophenylenediamine- aniline copolymer electrode. Anal Lett, 52(8):1282-1297

Aydın, E. B., Aydın, M., Sezgintürk, M.K. (2019).Biosensors and the evaluation of food contaminant biosensors in terms of their performance criteria. Int J Environ Anal Chem, DOİ:10.1080/03067319.2019.1672675

Bente, F., Hellstorm, T., Henrysdotter, G., Hjulmand-Lassen, M., Rüdinger, J., Sipilainen, Malm, T., Solli, E., Svensson, K., Tharkelsson, E.A., Tuomaala, V. (2000). Active and intelligent food packaging, a nordic report on legislative aspects. Nordic Concil of Ministers, 13-21, Copenhagen-Denmark.

Bouwmeester, H., Dekkers, S., Noordam, M.Y., Hagens, W.I., Bulder, A.S., Heer, C., Wijnhoven, S.W., Marvin, H.J., Sips, A.J. (2009). Review of health safety aspects of nanotechnologies in food production. Regul Toxicol Pharm, 53(1):52-62.

Buzby, J.C. (2010). Nanotechnology for food applications. More questions than answers. $J$ Consum Aff, 44(3):528- 545.

Chaudhry, Q., Scotter, M., Blackburn, J., Ross, B., Boxall, A., Castle, L., Aitken, R., Watkins, R. (2008). Applications and 57 implications of nanotechnologies for the food sector. Food Addit Contam, 25(3):241-258.

Cha, D.S., Chinnan, M.S. (2004). Biopolymerbased antimicrobial packaging: a review. Crit Rev Food Sci Nutr, 44(4):223-37.

Chau, C.F., Wu, S.H., Yen, G.C. (2007). The development of regulations for food nanotechnology. Trends Food Sci Technol, 18:169280.

Cui, Y., Wei, Q., Park, H., Lieber, C.M. (2001). Nanowire nanosensors for highly sensitive and selective detection of biological and chemical species. Sci, 293:1289-1292.

Cumbul Altay, M., Eroğlu, Ş. (2014). Karbon nanotüp sentezi için metan gazının kullanımı. AKU J Sci Eng, 14(OZ5739): 249-253.

Dang, T., Hu, W., Zhang, W., Song, Z., Wang, Y., Chen, M., Xu, H., Liu, G.L. (2019). Protein binding kinetics quantification via coupled 
plasmonic-photonic resonance nanosensors in generic microplate reader. Biosens Bioelectron, 142: 111494.

Das, M., Shim, K.H., Seong, S.A., Yi, D.K. (2011). Review on Gold Nanoparticles and Their Applications'Toxicol. Environ Health Sci, 3(4):193205.

Dawson, L.P., Acton, J.C., Ogale, A.A. (2002). Biopolymer films and potential applications to meat and poultry products. Fresh Meat / Packaging II. Proceedings of the 55th Annual Reciprocal Meat Conference, 75-82. Michigan- USA.

Dion, M., Luykx, A.M., Peters, R.J.B., Van Ruth, S.M., Bouwmeester, H. (2008). A review of analytical methods for the identification and characterization of nano delivery systems in food. J Agric Food Chem 56: 8231-8247.

Dhull, N., Kaur, G., Jain, P., Mishra, P., Singh, D., Ganju, L., Gupta, V., Tomar, M. (2019). Labelfree amperometric biosensor for Escherichia coli O157:H7 detection. Appl Surf Sci, 495:143548.

Elahi, N., Kamali, M., Hadi Baghersad, M., Amini, B. (2019). A fluorescence Nano-biosensors immobilization on Iron (MNPs) and gold (AuNPs) nanoparticles for detection of Shigella spp. Mater Sci Eng C, 105:110113.

Erdogan, A. (2018). Magnetic nanoparticles in the diagnosis and treatment of cancer. SDU J Nat Appl Sci, 1(1):23-30.

Flahaut, M.M.E., Serp, P., Razafinimanana, M. (2012). Introduction to carbon nanotubes. DOI: 10.1007/978-3-540-29857-13

Garcia, M., Aleixandre, M., Gutierrez, J., Horrillo, M.C. (2006). Electronic nose for wine discrimination. Sens Actuators B Chem, 113:911916.

Gong, X., Wang, H., Liu, Y., Hu, Q., Gao, Y., Yang, Z., Shuang, S., Dong, C. (2019). A difunctional and label-free carbon-based chemnanosensor for real-time monitoring of $\mathrm{pH}$ fluctuation and quantitative determining of Curcumin. Anal Chim Acta, 30;1057:132-144, doi: 10.1016/j.aca.2019.01.012
Gök, V., Batu, A., Telli, R. (2006). Ak1llı paketleme teknolojisi, Türkiye 9. Gida Kongresi, 2426 Mayıs, Bolu/Türkiye

Gök, V., (2007). G1da paketleme sanayinde akıllı paketleme teknolojisi, Gida Teknolojileri Elektronik Dergisi, (1): 45-58.

Gubin, S.P., Koksharov, Y.A., Khomutov, G.B., Yurkov, G.Y. (2005). Magnetic nanoparticles: preparation, structure and properties. Russ Chem Rev, 74 (6):489- 520.

Guillermo Fuertes, Ismael Soto, Raul Carrasco, Manuel Vargas, Jorge Sabattin, and Carolina Lagos. (2016). Intelligent Packaging Systems: Sensors and Nanosensors to Monitor Food Quality and Safety. J Sens, 8, DOİ:10.1155/2016/4046061

Irvine, G.W., Tan, S.N., Stillman, M.J. (2017). A Simple Metallothionein-Based Biosensor for Enhanced Detection of Arsenic and Mercury. Biosensors, 7:14

Jiménez-López, J., Rodrigues, S.S.M., Ribeiro, D.S.M., Ortega-Barrales P., Ruiz-Medina, A., Santos, J.L.M. (2019). Exploiting the fluorescence resonance energy transfer (FRET) between CdTe quantum noktas and Au nanoparticles for the determination of bioactive thiols. Spectrochim Acta A Mol Biomol Spectros, 212: 246-254.

Jafar1, A., Pourakbar, L., Farhad1, K., Mohamadgolizad1, L., Goosta, Y.(2015). Biological synthesis of silver nanoparticles and evaluation of antibacterial and antifungal properties of silver and copper nanoparticles, Turk J Biol, 39: 556-561

Joseph, T., Morrison, M. (2006). Nanotechnology in agriculture and food. Erişim Adresi: http://www.nanowerk.

$\mathrm{com} /$ nanotechnology/reports/reportpdf/report 61.pdf, Erişim tarihi: 27.02.2015.

Khan, N.I., Maddaus, A.G., Song, E. (2018). A Low-Cost Inkjet-Printed Aptamer-Based Electrochemical Biosensor for the Selective Detection of Lysozyme. Biosensors, 8: 7.

Kholoud, M.M., El-Nour, A., Eftaiha, A., AlWarthan,A., Ammar, R.A.A. (2010). Synthesis 
and applications of silver nanoparticles, Arab. J. Chem, 3: 135-140.

Kirwan, M.J., Strawbridge, J.W. (2003). Plastics in food packaging. R Coles, D McDowell and MJ Kirwan eds. Food Packag Technol, 174-240.

Kocaman, N., Sarımehmetoğlu, B. (2010). Gıdalarda akı1lı ambalaj kullanımı. Vet Hekim Der Dergisi, 81(2): 67-72.

Kumar, V., Guleria, P., Kumar Mehta, S. (2017). Nanosensors for food quality and safety assessment. Environ Chem Lett,15: 165-177, DOI:10.1007/s10311-017-0616-4.

Küçükyıldırım, B.O., Akdoğan Eker, A. (2012). Karbon Nanotüpler, Sentezleme Yöntemleri ve Kullanım Alanlan. TMMOB MMO Mühendis ve Makina Dergisi, 53(630): 34-44.

Li, Y., Zhang, Z., Tao, Z., Gao, X., Wang, S., Liu, Y. (2019). A Asp/Ce nanotube-based colorimetric nanosensor for $\mathrm{H}_{2} \mathrm{O}_{2}$-free and enzyme-free detection of cysteine, Talanta, 196:556-562

Li, Y., Hou, L., Shan, F., Zhang, Z., Li, Y., Liu Qiuchen Peng, Y., He, J., Li, K. (2019). A Novel Aggregation-Induced Emission Luminogen Based Molecularly Imprinted Fluorescence Sensor for Ratiometric Determination of Rhodamine B in Food Samples. Chemistry Select, 4: 11256-11261, DOI: 10.1002/slct.201903141

Lupan, O., Postica, V., Pauporté, T., Viana, B., Terasa, M.I., Adelung, R. (2019). Room temperature gas nanosensors based on individual and multiple networked Au-modified $\mathrm{ZnO}$ nanowires. Sens Actuators: B Chem, 299:126977.

Lupan, O., Postica, V., Wolff, N., Su, J., Labat, F., Ciofini, I., Cavers, H., Adelung, R., Polonskyi, O., Faupel, F., Kienle, L., Viana, B., Pauporté, T. (2019). Low-Temperature Solution Synthesis of Au-Modified $\mathrm{ZnO}$ Nanowires for Highly Efficient Hydrogen Nanosensors. ACS Appl Mater Interfaces, 11(35): 32115-32126

Mahmoudpoura, M., Ezzati Nazhad Dolatabadid, J., Torbatib, M., Pirpour Tazehkande, A., Homayouni-Radb, A., De la Guardia, M. (2019). Nanomaterials and new biorecognition molecules based surface plasmon resonance biosensors for mycotoxin detection. Biosens Bioelectron, 143:111603

Mcclements, D.J. (2011). Food-grade nanoemulsions: Formulation, fabrication, properties, performance, biological fate, and potential toxicity. Crit Rev Food Sci Nutr, 51: 285330.

Mukdasai, S., Uppachaib P., Srijaranai, S. (2019). A novel colorimetric paper sensor-based on the layer-by-layer assembled multilayers of surfactants for the sensitive and selective determination of total antioxidant capacity. RSC Adv, 9: 28598

Özkan, A., Atar, N., Yola, M.L. (2019). Enhanced surface plasmon resonance (SPR) signals based on immobilization of core-shell nanoparticles incorporated boron nitride nanosheets: Development of molecularly imprinted SPR nanosensor for anticancer drug, Etoposide. Biosens Bioelectron, 130:293-298.

Özkan Vardar, D., Aydın, S., Başaran, N. (2018). Kuantum Nokta Nanopartiküllerin Toksik Etkilerine Genel Bakış. J Lit Pharm Sci, 7(1):82-8.

Pandey, P., Dahiya, M. (2016). Carbon nanotubes: Types, methods of preparation and applications. Int J Pharm Sci, 1(4):15-21.

Park, J., Kuo, Y., Li, J., Huang, Y.L., Miller, E. W., Weiss, S. (2019). Improved Surface Functionalization and characterization of membrane targeted semiconductor voltage nanosensors. J Phys Chem Lett, 10 (14): 3906-3913.

Peng, D., Kavanagh, O., Gao, H., Zhang, X., Deng, S., Chen, D., Liu, Z., Xie, C., Situ, C., Yuan, Z. (2019). Surface plasmon resonance biosensor for the determination of 3-methylquinoxaline- 2carboxylic acid, the marker residue of olaquindox, in swine Tissues. Food Chem, 302:124623

Rauwel, P., Rauwel, E., Ferdov, S., Singh, M.P. (2015). Silver Nanoparticles: Synthesis, properties, and applications. Adv Mater Scu Eng, DOİ:10.1155/2015/624394

Rezende, J.P., Dias Ferreira, G.M., Mendes da Silva, L.H., Hepanhol da Silva, M.C., Pinto, M.S., Santos Pires, A.C.D.S. (2017). Polydiacetylene/triblock copolymer nanosensor 
for the detection of native and free bovine serum albümin. Mater Sci Eng C, 70:535-543.

Rhim, J.W., Hong, S.I., Park, H.M., Ng, K.W. (2006). Preparation and characterization of chitosan-based nanocomposite films with antimicrobial activity. J Agric Food Chem, 54(16):5814-5822.

Rios-Meraa, J. D., Saldañaa, E., Ramírezb, Y., Auquiñivínb, E. A., Alvimc, I. D., ContrerasCastillo, C. J. (2019). Encapsulation optimization and $\mathrm{pH}$-and temperature-stability of the complex coacervation between soy protein isolate and inulin entrapping fish oil. $L W T$ - Food Sci Technol, 116:108555

Robinson, D.K.R., Morrison, M.J. (2009). Nanotechnology developments for the agrifood sector - report of the observatory NANO. Erişim Adresi: http://nanopinion.eu/sites/ default/files/full_report_nanotechnology_in_agr ifood_may_2009pdf, Erişim Tarihi 05.03.2015.

Satapathi, S., Kumar, V., Kumar Chini, M.K., Bera, R., Halder, K.K., Patra. A. (2018). Highly sensitive detection and removal of mercury ion using a multimodal nanosensor. Nano-Structures \& Nano-Objects, 16: 120-126.

Selvolinia, G., Lettieria, M., Tassonib, L., Gastaldellob, S., Grillob, M., Maranb, C., Marrazza, G. (2019). Electrochemical enzymelinked oligonucleotide array for aflatoxin B1 Detection. Talanta, 203: 49-57

Serfert, Y., Drucsh, S., Schwarz, K. (2010). Sensory odour profiling and lipid oxidation status of fish oil and microencapsulated fish oil. Food Chem, 4: 968-975.

Shah, M., Badwaik, V., Kherde, Y., Kumar Waghwani, H., Modi, T., Aguilar, Z.P., Rodgers, H., Hamilton, W., Marutharaj, T., Webb, C., Lawrenz, M.B., Dakshinamurthy, R. (2014). Gold nanoparticles: various methods of synthesis and antibacterial applications, Front Brosc, 19:13201344.

Slepicka, P., Slepicková Kasálková, N., Siegel, J., Kolská, Z., Svorcík, V. (2020). Methods of Gold and Silver Nanoparticles Preparation. Materials, DOİ:10.3390/ma13010001
Srivastava, A. K., Dev, A., Karmakar, S., (2018). Nanosensors and nanobiosensors in food and agriculture. Environ Chem Lett, 16: 161-182.

Qian, J., Wang, K., Wang, C., Ren, C., Liu, Q., Hao, N., Wang, K. (2017). Ratiometric fluorescence nanosensor for selective and visualdetection of cadmium ions using quencher displacement-inducedfluorescence recovery of CdTe quantum noktas-based hybrid probe. Sens Actuators B, 241:1153-1160

Qian, L., Wang, K., Zhu, W., Han, C., Yan, C. (2019). Enhanced sensing ability in a single-layer guided-mode resonant optical biosensor with deep grating, Opt Commun, 452: 273-280.

Teixeira, A., Hernández-Rodríguez, J. F., Wu L., Oliveira, K., Kant, K., Piairo, P., Diéguez, L., Abalde-Cela, S. (2019). Microfluidics-Driven Fabrication of a Low Cost and Ultrasensitive SERS-Based Paper Biosensor. Appl Sci, 9: 1387, DOİ:10.3390/app9071387

Torres-Giner, S., Gimenez, E., Lagaron, J.M. (2007). Characterization of the morphology and thermal properties of Zein Prolamine nanostructures obtained by electrospinning. Food Hydrocoll, 22: 601-614.

Tüylek, Z. (2017). Biyosensörler ve nanoteknolojik etkileşim, BEUJ Sci, 6(2), 71-80.

Veglia, A.V., Guillermo Bracamonte, A.(2019). $\beta$ Cyclodextrin grafted gold nanoparticles with short molecular spacers applied for nanosensors based on plasmonic effects. Microchem J, 148:277284

Wang, H., Rao, H., Luo, M., Xue, X., Xue, Z., Lu, X. (2019). Noble metal nanoparticles growthbased colorimetric strategies: From monocolorimetric to multicolorimetric sensors. Coord Chem Rev, 398:113003

Wu, J., Zeng, L., Li, N., Liu, C., Chen, J. (2019). A wash-free and label-free colorimetric biosensor for naked-eye detection of aflatoxin B1 using Gquadruplex as the signal reporter. Food Chem, 298:125034.

Xiang, Y., Camarada, M.B., Wen, Y., Wu, H., Chen, J., Li, M., Liao, X. (2018). Simple voltammetric analyses of ochratoxin A in food 
samples using highly-stable and anti-fouling black phosphorene nanosensor. Electrocbim Acta, 282: 490-498.

Valizadeh, A., Mikaeili, H., Samiei, M., Mussa Farkhani, S., Zarghami, N., Kouhi, M., Akbarzadeh, A., Davaran, S. (2012). Quantum dots: synthesis, bioapplications, and toxicity. Nanoscale Res Lett, 7: 480.

Vatta, L. L., Sanderson, R. D., Koch, K. R. (2006). Magnetic nanoparticles: Properties and potential applications. Pure Appl Chem, 78(9):1793-1801. DOİ: $10.1351 /$ pac200678091801.

Yadav, J. (2018). Synthesis and characterization of gold nanoparticles. Internationa Journal on Future Revolution in Computer Science \& Communication Engineering, 4(4): 220-230

Zhou, Y., Ding, L., Wu, Y., Huang, X., Lai, W., Xiong, Y. (2019). Emerging strategies to develop sensitive AuNP-based ICTS Nanosensors. TracTrend Anal Chem, 112:147-160.

Ziyaina, M., Rasco, B., Coffey, T., Ünlü, G., Sablani, S. S. (2019). Colorimetric detection of volatile organic compounds for shelf-life monitoring of milk. Food Control, 100: 220-226.

Zhao, Y., Gosai, A., Shrotriya, P. (2019). Effect of receptor attachment on sensitivity of label free microcantilever based biosensor using malachite green aptamer, Sens Actuators: B Chem, 300:126963.

Zulli, F., Belser, E., Schmid, D., Liechti, C., Suter, F. (2006). Preparation and properties of Coenzyme Q10 nanoemulsions. Cosmet Sci Technol, 40-46. 